\title{
Prevalence of needlestick injuries among nursing interns: a systematic review and meta-analysis
}

\author{
Meitong Chen, Lijuan Zhang \\ Hubei NO.3 People's Hospital of Jianghan University, Wuhan, China \\ Contributions: (I) Conception and design: M Chen; (II) Administrative support: M Chen; (III) Provision of study materials or patients: M Chen; \\ (IV) Collection and assembly of data: L Zhang; (V) Data analysis and interpretation: L Zhang; (VI) Manuscript writing: Both authors; (VII) Final \\ approval of manuscript: Both authors. \\ Correspondence to: Lijuan Zhang. Hubei NO.3 People's Hospital of Jianghan University, 26 Zhongshan Avenue, Qiaokou District, Wuhan, China. \\ Email: 18627757602@139.com.
}

\begin{abstract}
Backgroundk The aim of the present study was to analyze the prevalence of needlestick injuries (NSI) of trainee nursing students and to understand the cause of injury and psychological reactions following injury, and take corresponding countermeasures to prevent adverse consequences.

Methods: Multiple databases were used to search for articles related to NSI among nursing interns. The selected literature was retrospectively evaluated by using Review Manager version 5.2.

Results: According to the analysis of 8 published studies, the lowest overall prevalence of NSI occupational exposure was 6\% [95\% confidence interval (CI): 3-9\%], the highest was 51\% (95\% CI: 42-60\%), and the total combined prevalence was $27 \%$ (95\% CI: 18-37\%). The overall prevalence rate of interns under 25 years old was 31\% (95\% CI: 7-69\%), and that of interns over 25 years old was 26\% (95\% CI: 15-38\%). The overall prevalence of interns was 38\% (95\% CI: 16-61\%) in developing countries and 21\% (95\% CI: $11-31 \%$ ) in developed countries. The overall prevalence of interns was 38\% (95\% CI: 16-61\%) in Asian countries, 9\% (95\% CI: 3-15\%) in the United States, and 30\% (95\% CI: 3-57\%) in European countries.

Discussion: The results showed that interns over 25 years of age were more likely to have NSI, and interns in developing countries were more likely to have NSI than those in developed countries. Interns in Asia were more likely to have NSI than interns in Europe, and the lowest incidence of NSI was among interns in the USA.
\end{abstract}

Keywords: Prevalence; needlestick injuries (NSI); nursing interns

Submitted Feb 26, 2021. Accepted for publication Jul 06, 2021.

doi: 10.21037/apm-21-703

View this article at: http://dx.doi.org/10.21037/apm-21-703

\section{Introduction}

Clinical practice is the only way for nursing students to gain experience. However, given the special nature of hospital work, nursing students face various occupational hazards during clinical practice, among which needlestick injuries (NSI) are the most common (1-3). NSI usually occur in medical staff in hospitals, clinics and laboratories. If needles are not properly discarded, NSI can also happen at home or in the community. Used needles may contain blood or body fluids carrying HIV, hepatitis B virus (HBV) or hepatitis $\mathrm{C}$ virus (HCV). The virus can spread to people whose needles have stabbed in infected people $(4,5)$. A number of studies have confirmed that nurses are a high-risk group of sharps injuries in the hospital. Due to unfamiliar environments, unfamiliar skills, and lack of clinical experience and professional knowledge of occupational protection, interns are more likely to have sharps injuries than in-service nurses $(4,5)$.

An NSI is an accidental injury deep in the skin that can cause the injured person to bleed. It is the most common occupational injury in medical care. American surveys have found that $60-90 \%$ of NSI are caused by nursing staff. 
More than 20 blood-borne diseases can be transmitted through NSI (6-8). Sharps injuries are caused by medical sharp instruments, such as syringe needles, stitches, various puncture needles, scalpels, and ampoules, causing skin injuries deep enough to cause bleeding (9).

Infected NSI and other sharp object injuries are occupational factors that can cause health workers to develop blood-borne diseases $(9,10)$. Intern nurses are unskilled, lack clinical experience and professional knowledge of occupational protection, and have a greater chance of NSI. Stabbing by injection needles or other medical sharps in medical care is the most common occupational injury, which can lead to blood exposure of medical staff, and increase the risk of HBV, HCV, HIV, and other infections (11-13). Due to unfamiliar skills and lack of clinical experience and corresponding occupational protection knowledge, interns are more vulnerable to the danger of occupational infection than in-service nurses $(14,15)$.

In order to explore the NSI protection knowledge of nursing students, analyze the incidence of NSI, and develop the safety awareness for nursing students, we conducted this meta-analysis. In this research, we divided data based on social-economic situation and development of country and conducted analysis in the subgroups. We present the following article in accordance with the PRISMA reporting checklist (available at https://dx.doi. org/10.21037/apm-21-703).

\section{Methods}

\section{Literature search strategy}

Studies published in English from 2002 to 2021 were reviewed, and 4 electronic databases (PubMed, Embase, Cochrane Library, and China Academic Journals Full-text Database) were searched with biological operators (and, or) to analyze the included literature.

\section{Study selection}

After primary selection of the studies, studies that were potentially relevant were reviewed. The inclusion criteria were nursing interns and NSI.

\section{Data extraction and quality assessment}

Two reviewers independently scanned the full text of the articles, and the following data were retrieved from each eligible study: first author's name, year of publication, language of included articles, country of origin, sample age, sample size, and study period of each article. A riskof-bias assessment was conducted using the Cochrane Collaboration tool for assessing risk of bias.

\section{Statistical analysis}

Statistical analyses were performed using Review Manager (version 5.2, Cochrane Collaboration, Copenhagen, Denmark, 2011) and STATA 12.0 (StataCorp LP, College Station, TX, USA). In brief, to measure the consistency of the effect size (OR and $M D)$, pairwise meta-analyses were performed with a DerSimonian and Laird random effects model to calculate the pooled estimates of OR and MD with $95 \%$ CIs of direct comparisons. A $\chi^{2}$-based homogeneity test was performed and the inconsistency index $\left(\mathrm{I}^{2}\right)$ statistic was determined. Fixed-effects models were used in the absence of heterogeneity, otherwise random-effects models were used. Begg's test was performed to assess potential publication bias. In addition, further sensitivity analyses were performed.

\section{Results}

\section{Search process}

The electronic search ended with 840 articles. After careful reading, 85 papers were considered to have met the preliminary standard. After further screening, 77 articles were excluded due to unclear objectives and non-compliant. Finally, 8 papers were selected for analysis. Figure 1 was a flowchart which included identification, inclusion and exclusion with reasons and it reflected the search process.

\section{Characteristics of the included studies}

The detailed characteristics of the included studies are shown in Table 1. These included the first author, publication year, language, country of origin, sample age, sample size, and research period of each article (16-23). All of the studies were published from 1999 to 2017, with sample sizes ranging from 180 to 1,403 participants.

\section{Results of the quality assessment}

The included articles were evaluated by the Cochrane risk of bias assessment tool to assess their quality (Figures 2,3). From the quality assessment results, we found that only 1 article had selection bias and 1 had reporting bias while 


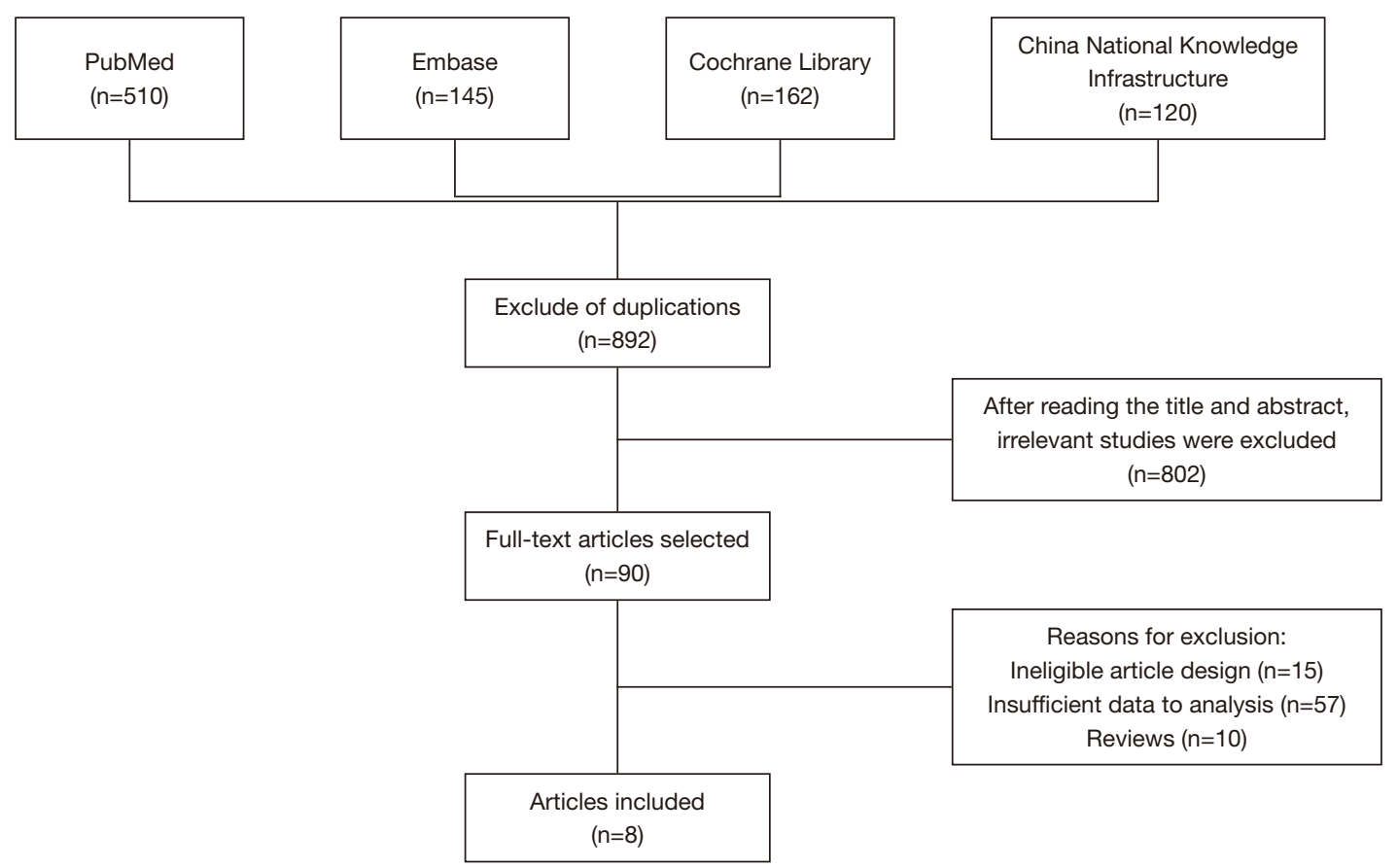

Figure 1 Flow diagram of studies for inclusion in the systematic review and meta-analysis.

Table 1 Characteristics of the studies included in the meta-analysis

\begin{tabular}{lllllll}
\hline Study & Year & Language & Country & Age range (mean) & No. researchers & Years of onset \\
\hline Cheung & 2010 & English & China & $21.14 \pm 1.36$ & 267 & January 2002 to December 2006 \\
Jonczyk & 2018 & English & Poland & $45 \pm 5.2$ & 107 & March 2017 to April 2017 \\
Katsevman & 2020 & English & USA & $26 \pm 5.5$ & 289 & May 2007 to July 2009 \\
Reid & 2014 & English & USA & $21 \pm 1.2$ & 180 & June 2007 to August 2013 \\
Rubbi & 2018 & English & Italy & $20 \pm 2.5$ & 1,403 & December 2009 to March 2017 \\
Unver & 2012 & English & Turkey & $20.75 \pm 1.04$ & 218 & June 2007 to June 2009 \\
Wang & 2003 & English & China & $18 \pm 3$ & 106 & September 2000 to April 2001 \\
Yang & 2007 & English & China & $17.8 \pm 0.6$ & 107 & July 1999 to December 1999 \\
\hline
\end{tabular}

other 6 researches had no bias. Overall, the quality of included articles was good.

\section{Results of the heterogeneity test}

Among the 8 articles included in the present study, the lowest overall prevalence of occupational exposure to NSI was 6\% (95\% CI: 3-9\%), the highest was 51\% (95\% CI: $42-60 \%)$, and the total combined prevalence was $27 \%(95 \%$ CI: $18-37 \%, \mathrm{P}=0.000$ ) (Figure 4).

In terms of age, the lowest and highest prevalence were
12\% (95\% CI: 8-16\%) and 51\% (95\% CI: 42-60\%) among medical staff over 25 years of age, respectively. The lowest and highest prevalence was 6\% (95\% CI: 3-9\%) and 50\% (95\% CI: 41-59\%) among medical staff under 25 years of age, respectively. The overall prevalence was 27\% (95\% CI: $18-37 \%, \mathrm{P}=0.000$ ) (Figure 5).

According to socio-economic situation, the lowest prevalence of medical staff in developed countries exposed to NSI in their careers was 19\% (95\% CI: 14-24\%), and the highest prevalence was 50\% (95\% CI: 41-59\%). The lowest prevalence of medical staff in developing countries 


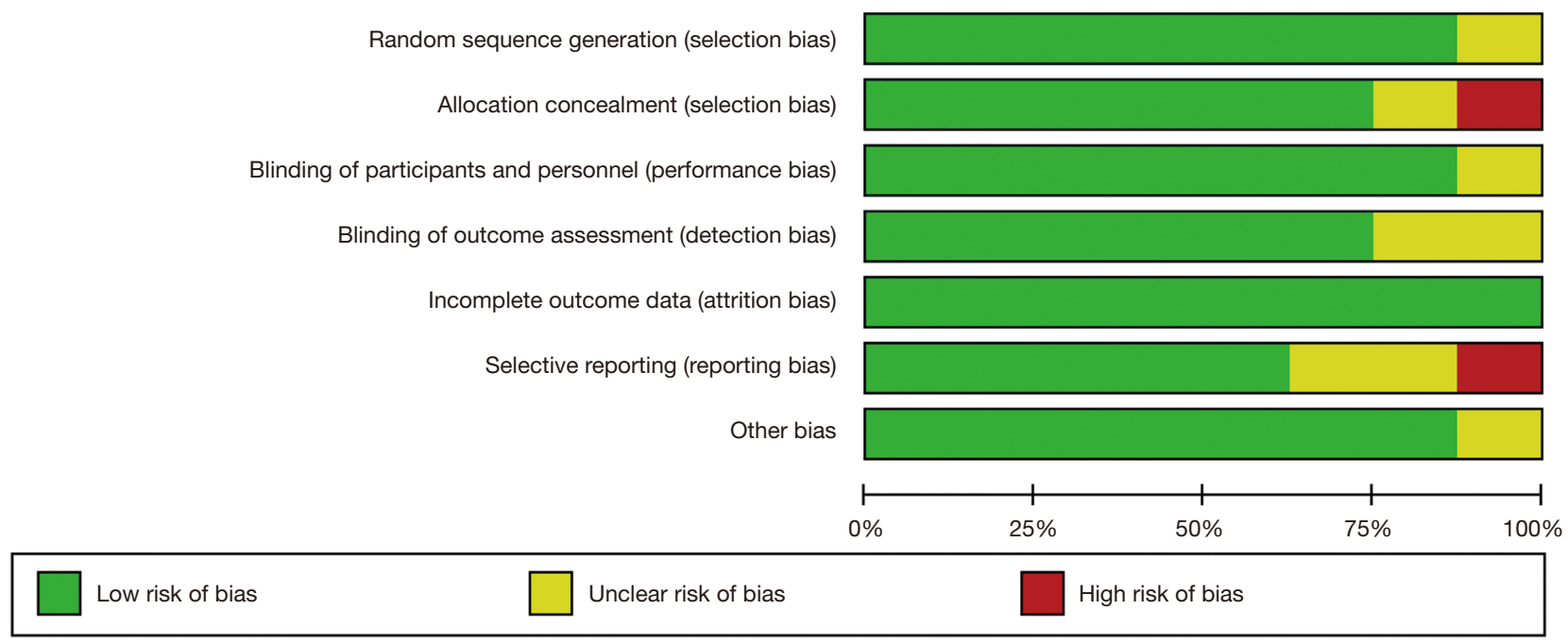

Figure 2 Assessment of the quality of the included studies: low risk of bias (green), unclear risk of bias (yellow), and high risk of bias (red).

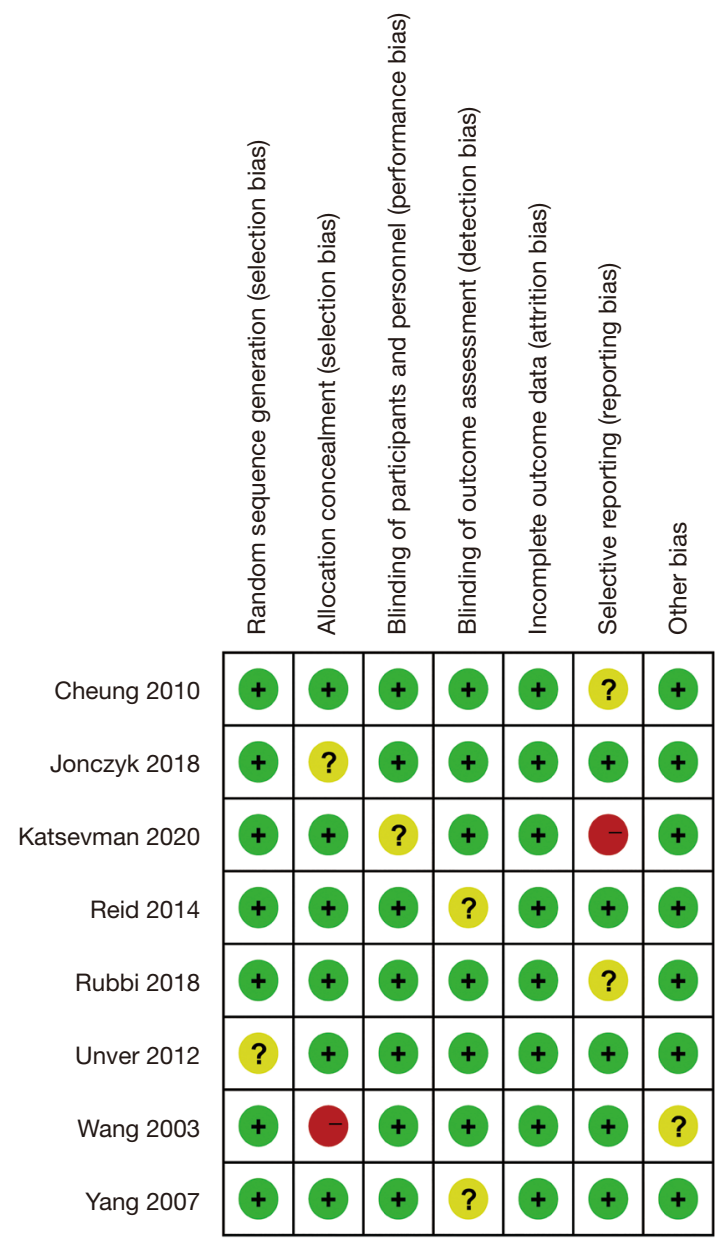

Figure 3 Quality assessment of included studies: low risk of bias (green), unclear risk of bias (yellow), and high risk of bias (red). exposed to NSI in their careers was 6\% (95\% CI: 3-9\%), and the highest prevalence was 51\% (95\% CI: 42-60\%). The overall combined prevalence of medical staff's career exposure to NSI was $27 \%$ (95\% CI: $18-37 \%, \mathrm{P}=0.000$ ) (Figure 6).

From a regional point of view, the lowest prevalence of Asian medical staff occupationally exposed to NSI was $19 \%$ (95\% CI: 14-24\%), and the highest prevalence was $50 \%$ (95\% CI: 41-59\%). The lowest prevalence of medical workers in the USA with occupational exposure to NSI was 6\% (95\% CI: 3-9\%), and the highest collective prevalence was $12 \%$ (95\% CI: $8-16 \%)$. The lowest prevalence of medical workers in Europe with occupational exposure to NSI was 6\% (95\% CI: 5-7\%), and the highest collective prevalence was 51\% (95\% CI: 42-60\%). The overall comprehensive prevalence of medical personnel's occupational exposure to NSI was 27\% (95\% CI: 18-37\%, $\mathrm{P}=0.000)$ (Figure 7).

\section{Discussion}

Medical sharp instrument injuries are one of the most common occupational injuries in nursing. A variety of blood-borne diseases can be transmitted via this method (24-26). Studies have shown that nurses are a high-risk group for medical sharp instrument injuries and bloodborne diseases. Due to lack of practical experience, knowledge of protection, and unfamiliar skills, the risk probability of sharp instrument injuries is greater.

Sharp instrument injuries are the main cause of 


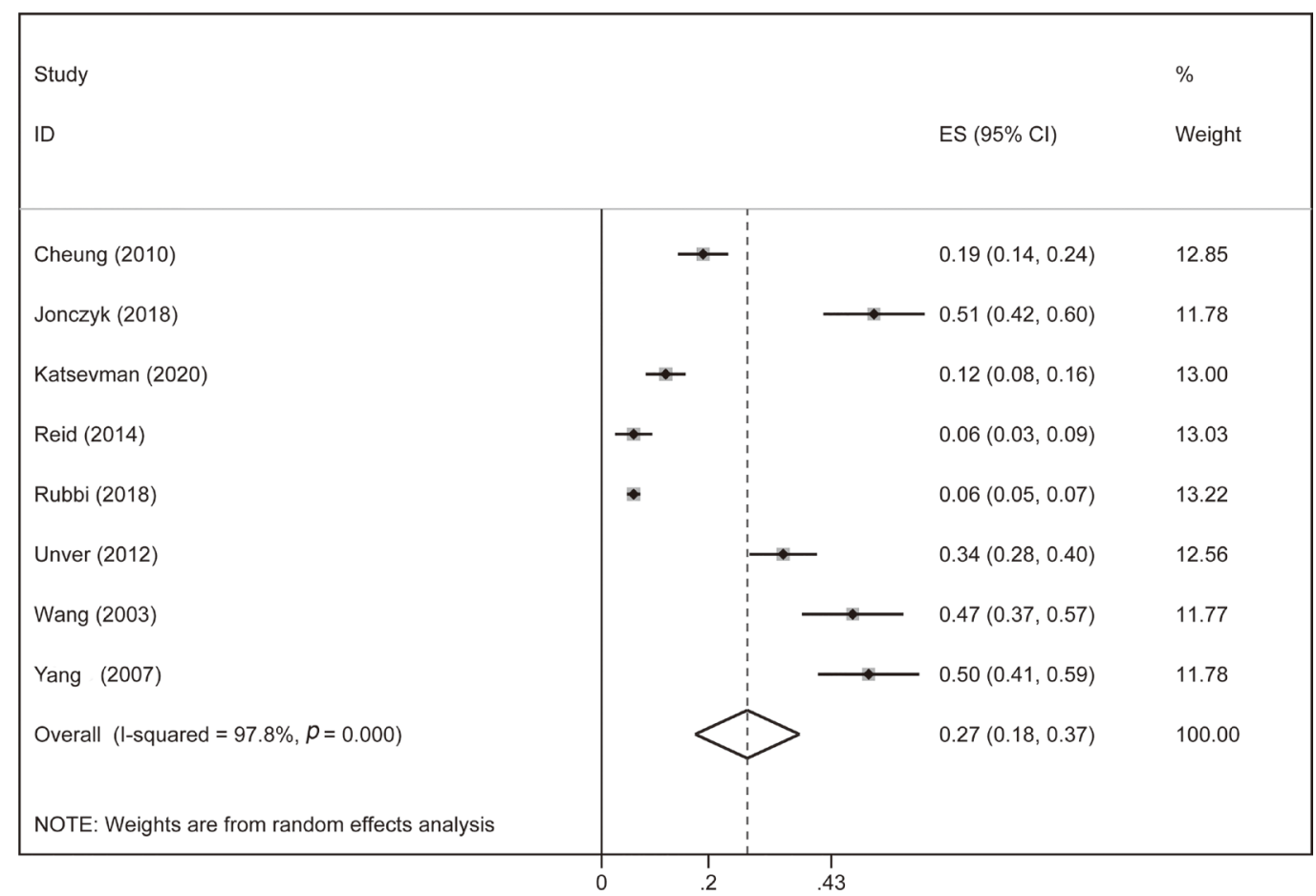

Figure 4 Forest map of the overall prevalence of needlestick injuries. CI, confidence interval; ES, effect size.

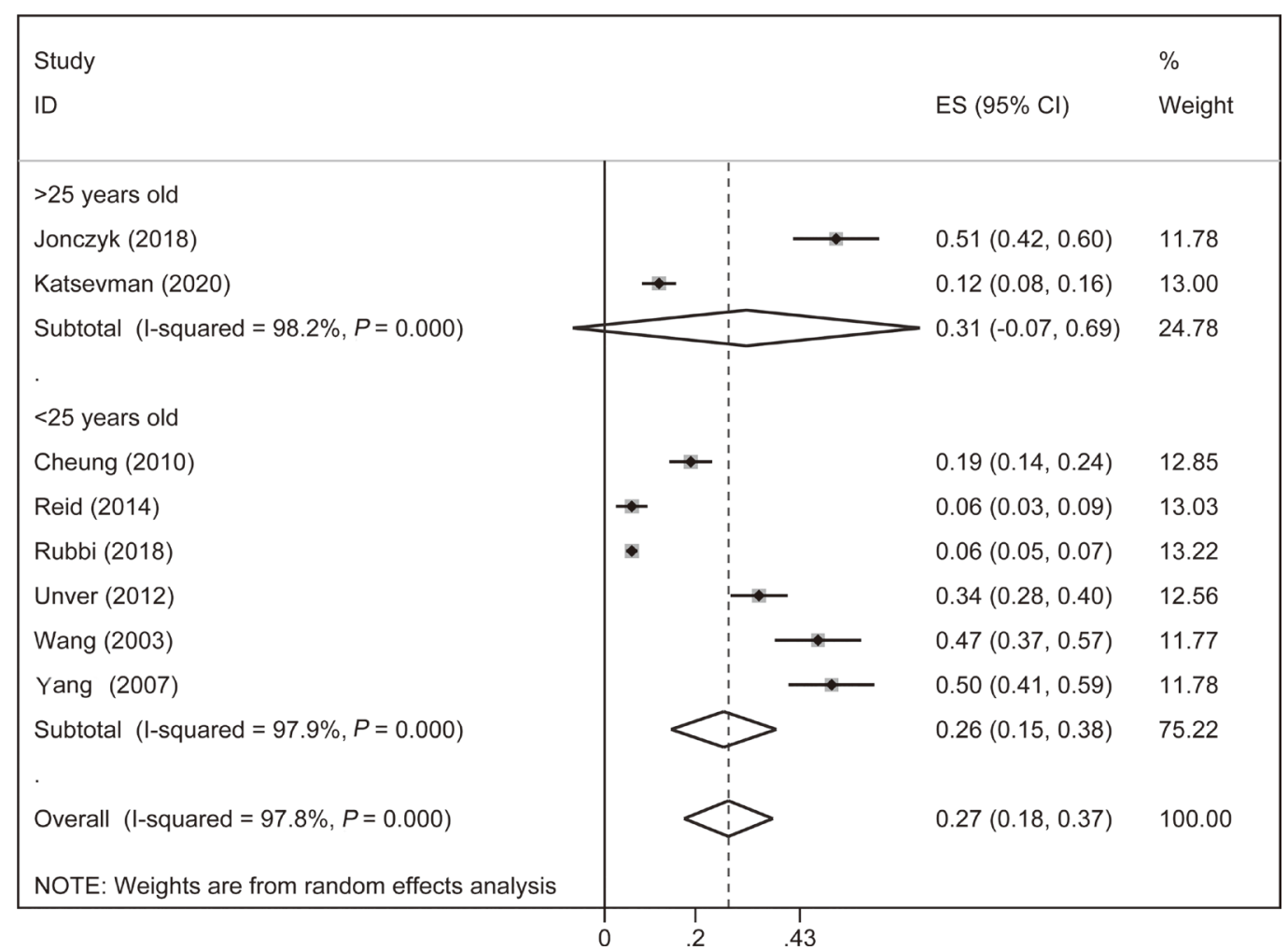

Figure 5 Forest map of the prevalence of needlestick injuries by age. CI, confidence interval; ES, effect size. 


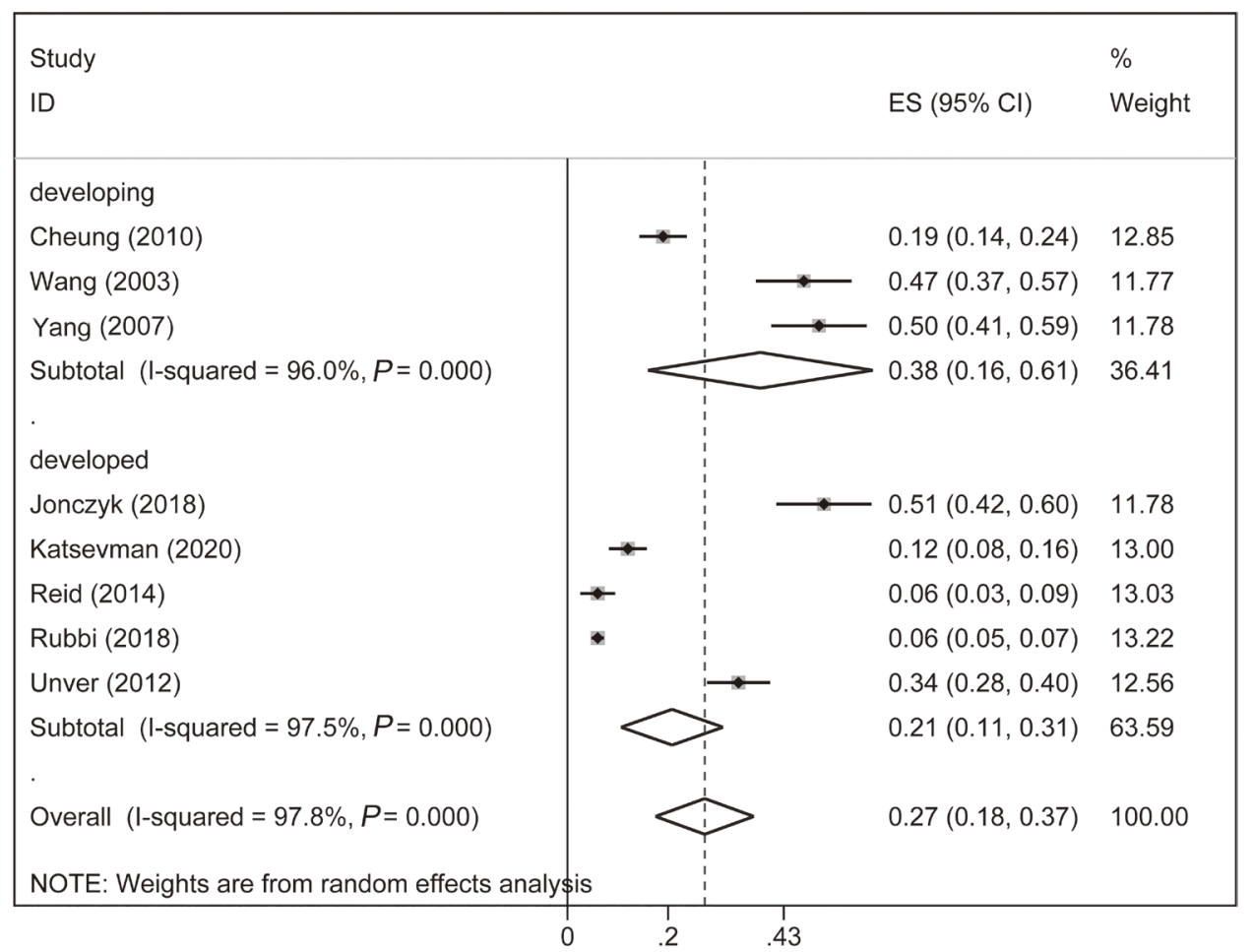

Figure 6 Forest map of the prevalence of needlestick injuries by socioeconomic development. CI, confidence interval; ES, effect size.

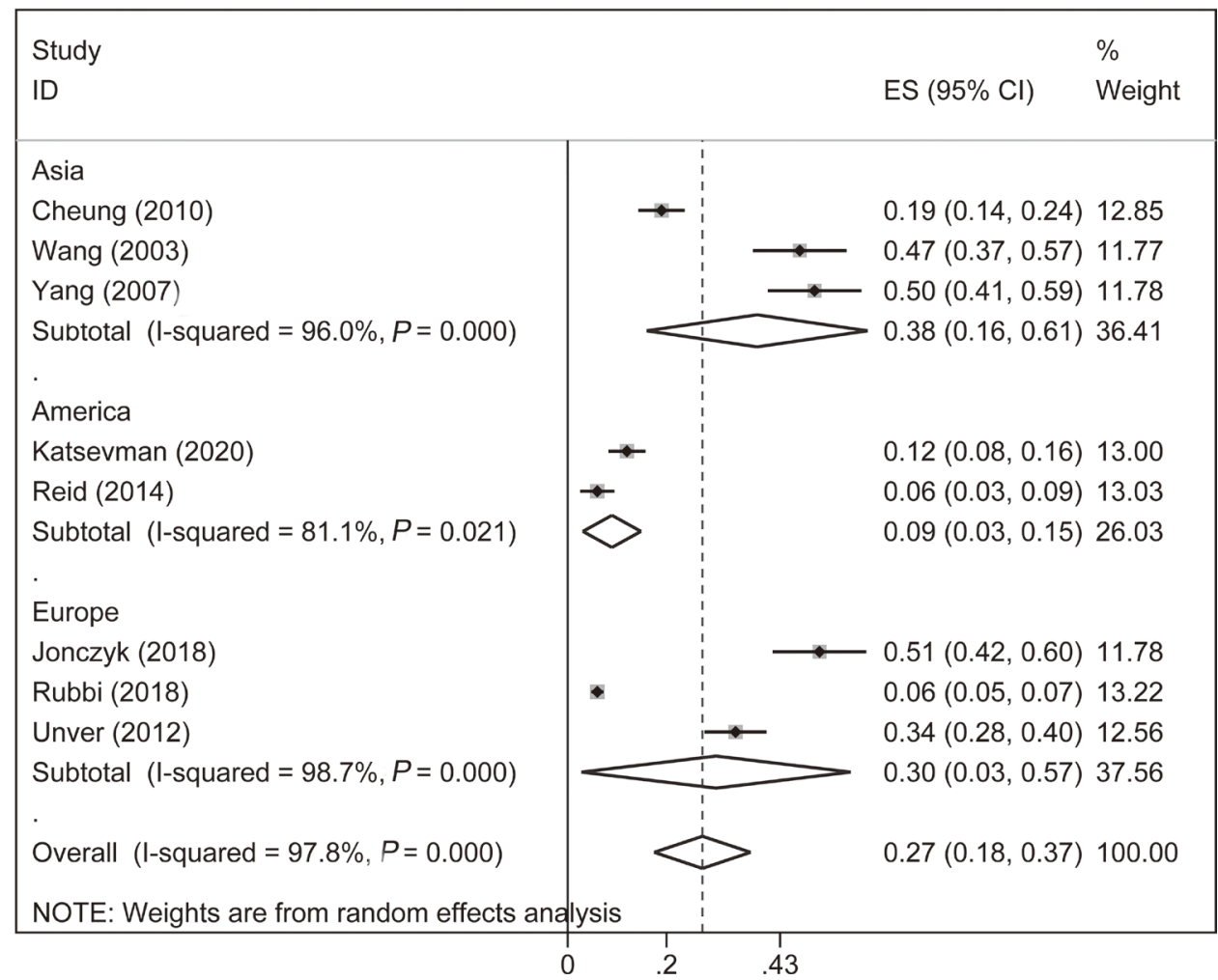

Figure 7 Forest map of the prevalence of needlestick injuries in different geographical areas. CI, confidence interval; ES, effect size. 
occupational injury among nurses $(27,28)$. More than 20 blood-borne diseases, including AIDS, hepatitis B, and hepatitis $\mathrm{C}$, can be caused by at least 1 million accidental NSI worldwide (29-31). The risk of blood- and body fluidborne diseases after sharp instrument injury is much higher than that of skin and mucous membrane contact. Therefore, medical staff, particularly nursing interns, are at high risk of severe occupational exposure (32-34).

We should strengthen the training of safe operation skills, do a good job in the guidance of occupational protection; prevent NSI and glass injuries, strictly manage medical waste, prevent NSI and glass injuries should be put in the first place of occupational protection education; establish and improve the registration and reporting system of interns after injury; reasonably arrange working hours, add occupational protection courses, cultivate occupational protection skills, and strengthen occupational protection, education, and strengthen the awareness of occupational safety $(35,36)$. To prevent NSI, we also need to follow these rules: always use gloves when you handle needles that are exposed to blood or other body fluids; do not recap needles after use and throw away needles in a safe container.

In conclusion, our findings indicated that interns aged over 25 years were more prone to NSI and faced serious occupational exposure risk than interns under the age of 25 , which was consistent with the literature $(17,18)$. However, the present study has some limitations. First, the comparison between Africa and Oceania was not taken into account and should be evaluated in further studies. Second, more indicators evaluating NSI of nursing interns should be included in future studies.

\section{Acknowledgments}

Funding: None.

\section{Footnote}

Reporting Checklist: The authors have completed the PRISMA reporting checklist. Available at https://dx.doi. org/10.21037/apm-21-703

Conflicts of Interest: Both authors have completed the ICMJE uniform disclosure form (available at https://dx.doi. org/10.21037/apm-21-703). Both authors have no conflicts of interest to declare.

Ethical Statement: The authors are accountable for all aspects of the work in ensuring that questions related to the accuracy or integrity of any part of the work are appropriately investigated and resolved.

Open Access Statement: This is an Open Access article distributed in accordance with the Creative Commons Attribution-NonCommercial-NoDerivs 4.0 International License (CC BY-NC-ND 4.0), which permits the noncommercial replication and distribution of the article with the strict proviso that no changes or edits are made and the original work is properly cited (including links to both the formal publication through the relevant DOI and the license). See: https://creativecommons.org/licenses/by-nc-nd/4.0/.

\section{References}

1. Ahmed Saleh AM, Adam SM, Ibrahim AMA, et al. A training program for nursing staff regarding blood parasites acquired by needle stick injury in a military hospital. J Egypt Soc Parasitol 2017;47:65-80.

2. Sardesai RV, Gaurkar SP, Sardesai VR, et al. Awareness of needle-stick injuries among health-care workers in a tertiary health-care center. Indian J Sex Transm Dis AIDS 2018;39:107-10.

3. Costa MD, Rapparini C, Schmaltz CAS, et al. Danger in the streets: exposures to bloodborne pathogens after community sharp injuries in Rio de Janeiro, Brazil. Braz J Infect Dis 2017;21:306-11.

4. El-Hay SA, Allah AA. Effect of Implementing Training Module on Competence of Internship Nursing Students Performance regarding Needle Stick and Sharp Injuries Safety Issues. Tanta Scientific Nursing Journal 2020;19:152-80.

5. Wu SH, Huang CC, Huang SS, et al. Effect of virtual reality training to decreases rates of needle stick/sharp injuries in new-coming medical and nursing interns in Taiwan. J Educ Eval Health Prof 2020;17:1.

6. Senthilnayagam K, Sivaponnappan K. Emergency management of traumatic dental injuries among nursing interns- cronbach's alpha reliability analysis and percentage analysis. Journal of Evidence Based Medicine and Healthcare 2019;6:1270-6.

7. Ibrahim AF, Akel DT, Abd El Fatah LAM, et al. Emotional intelligence and internet addiction among nursing interns. Clinical Nursing Studies 2016;4:70-80.

8. Woldesonbet DZ. Epidemiology of needle stick-sharp injuries (NSSIs) and potential high risk exposures among health professionals in Ethiopia: Neglected public health 
concern. Int J Infect Dis 2016;45:249-50.

9. Choi MJ, Chaung SK, Park JH, et al. Exposure to Needlestick and Sharp Injuries, Anxiety during Injection Practice and Experience of Injecting Human Beings in Fundamental Injection Practice. Journal of Korean Academy of Fundamentals of Nursing 2018;25:231-9.

10. Bekele T, Gebremariam A, Kaso M, et al. Factors Associated with Occupational Needle Stick and Sharps Injuries among Hospital Healthcare Workers in Bale Zone, Southeast Ethiopia. PLoS One 2015;10:e0140382.

11. Akhuleh OZ, Nasiri E, Heidari M, et al. Frequency of sharp injuries and its related factors among high-risk wards staff. J Nurs Midwifery Sci 2019;6:204-9.

12. Rubinson L. From clinician to suspect case: my experience after a needle stick in an Ebola treatment unit in Sierra Leone. Am J Trop Med Hyg 2015;92:225-6.

13. Geravandi S, Moogahi S, Kayedi N, et al. Investigation of Sharp Injuries in an Educational Hospital, Ahvaz, Iran. Arch Hyg Sci 2017;6:10-6.

14. Lee C, Jang EJ, Kwon D, et al. Laboratory-acquired dengue virus infection by needlestick injury: a case report, South Korea, 2014. Ann Occup Environ Med 2016;28:16.

15. Liyew B, Sultan M, Michael M, et al. Magnitude and Determinants of Needlestick and Sharp Injuries among Nurses Working in Tikur Anbessa Specialized Hospital, Addis Ababa, Ethiopia. Biomed Res Int 2020;2020:6295841.

16. Wang H, Fennie K, He G, et al. A training programme for prevention of occupational exposure to bloodborne pathogens: impact on knowledge, behaviour and incidence of needle stick injuries among student nurses in Changsha, People's Republic of China. J Adv Nurs 2003;41:187-94.

17. Cheung K, Ho SC, Ching SS, et al. Analysis of needlestick injuries among nursing students in Hong Kong. Accid Anal Prev 2010;42:1744-50.

18. Rubbi I, Cremonini V, Butuc A, et al. Incidence and type of health care associated injuries among nursing students: an experience in northern Italy. Acta Biomed 2018;89:41-9.

19. Jończyk A, Szczypta A, Talaga-Ćwiertnia K. Injuries as exposure events in providing medical services by nursing staff Przegl Epidemiol 2018;72:371-81.

20. Katsevman GA, Sedney CL, Braca Iii JA, et al. Interdisciplinary differences in needlestick injuries among healthcare professionals in training: Improving situational awareness to prevent high-risk injuries. Work 2020;65:635-45.

21. Reid MJ, Biller N, Lyon SM, et al. Reducing risk and enhancing education: U.S. medical students on global health electives. Am J Infect Control 2014;42:1319-21.

22. Yang YH, Liou SH, Chen CJ, et al. The effectiveness of a training program on reducing needlestick injuries/sharp object injuries among soon graduate vocational nursing school students in southern Taiwan. J Occup Health 2007;49:424-9.

23. Unver V, Tastan S, Coskun $H$. The frequency and causes of occupational injuries among nursing students in Turkey. Arch Environ Occup Health 2012;67:72-7.

24. Musa S, Peek-Asa C, Young T, et al. Needle Stick Injuries, Sharp Injuries and other Occupational Exposures to Blood and Body Fluids among Health Care Workers in a general hospital in Sarajevo, Bosnia and Herzegovina. Int J Occup Saf Health 2014;4:31-7.

25. Amini M, Behzadnia MJ, Saboori F, et al. Needle-Stick Injuries Among Healthcare Workers in a Teaching Hospital. Trauma Mon 2015;20:e18829.

26. Abdifard E, Sepahvand E, Aghaei A, et al. Needle-Stick, Sharp Injuries, and Its Related Factors among Nurses of Imam Reza Hospital, Kermanshah, Iran. JCCNC 2015;1:183-8.

27. Chaung SK, Choi MJ, Park JH, et al. Nursing Students' Exposure to NeedleStick and Sharp Injuries, Faculty's Stress and Necessity of Informed Consent in Fundamental Nursing Practice. Journal of the Korean Academy of Fundamentals of Nursing 2017;24:277-85.

28. Dilie A, Amare D, Gualu T. Occupational Exposure to Needle Stick and Sharp Injuries and Associated Factors among Health Care Workers in Awi Zone, Amhara Regional State, Northwest Ethiopia, 2016. J Environ Public Health 2017;2017:2438713.

29. Wimalasena TB, Liyanarachchi ND, Wijesinghe CJ, et al. Occupational exposure to sharps injuries among doctors working in two Teaching Hospitals in the Southern Province. Journal of the Ruhunu Clinical Society 2015;20:11.

30. Chen Y, Jia B, Huang R, et al. Occupational Severe Fever With Thrombocytopenia Syndrome Following Needle-Stick Injury. Infect Control Hosp Epidemiol 2017;38:760-2.

31. Sharma R, Gupta P, Jelly P. Pattern and serological profile of healthcare workers with needle-stick and sharp injuries: A retrospective analysis. J Family Med Prim Care 2020;9:1391-6.

32. Quynh ATT, Einhellig K. Practices for prevention needlestick and sharps injuries among nursing students. Belitung Nursing Journal 2017;3:183-90.

33. AlDakhil L, Yenugadhati N, Al-Seraihi O, et al. Prevalence 
and associated factors for needlestick and sharp injuries (NSIs) among dental assistants in Jeddah, Saudi Arabia. Environ Health Prev Med 2019;24:60.

34. Megnath A, Nusrath A, Rani NA. Prevalence of Needle Stick Injury among Interns of Rural Medical Teaching Hospital. J Med Sci Hea 2017;3:14-9.

35. Garcia VH, Radon K. Preventive Training among Medical Interns in Mexico City and Its Association with
Needlestick and Sharp Injuries - A Cross Sectional Study. J Clin Diagn Res 2017;11:IC05-7.

36. Choi LY, Torres R, Syed S, et al. Sharps and Needlestick Injuries Among Medical Students, Surgical Residents, Faculty, and Operating Room Staff at a Single Academic Institution. J Surg Educ 2017;74:131-6.

(English Language Editor: R. Scott)

Cite this article as: Chen $M$, Zhang L. Prevalence of needlestick injuries among nursing interns: a systematic review and meta-analysis. Ann Palliat Med 2021;10(7):7525-7533. doi: 10.21037/apm-21-703 